\title{
DEFINITION OF PROJECT-BASED LEARNING MODELS IN THE COMPUTER ENGINEERING DEGREE
}

\author{
Javier Esparza-Peidro1', Emilio Golf², Juan Jesús Izquierdo-Doménech', \\ José-Vicente Tomás-Miquel ${ }^{2}$, Raquel Sanchis ${ }^{2}$ \\ ${ }^{1}$ Dpto. de Sistemas Informáticos y Computación, Escuela Politécnica Superior de Alcoy. \\ Universitat Politècnica de València (SPAIN) \\ ${ }^{2}$ Dpto. de Organización de Empresas, Escuela Politécnica Superior de Alcoy. Universitat \\ Politècnica de València (SPAIN)
}

\begin{abstract}
The current characteristics, concerns, preferences, and interests of students differ greatly from the previous students' generations. Nowadays, students are increasingly demanding active methodologies that facilitate their learning process. To meet the actual students' requirements, academic research is focused on the definition of educational mechanisms that promote greater students' participation.

Among these mechanisms, the project-based learning (PBL) is a model that organizes learning around projects. Projects are student-driven and provide more tangible results what has been considered as a positive aspect to deepen and retain knowledge. The main objective of this paper is to describe all the activities performed to plan, define, design and project an integrated PBL model for students in the last years (3rd and 4th year students) of the Computer Engineering Degree. The PBL model involves the following subjects: (i) Software Engineering; (ii) Project Management; (ii) Business Requirements Analysis and (iv) Business Models and Organisation Functional Areas. The PBL model has twofold perspectives, the first one is more project and software-directed while the second one is more businessoriented. This model seeks to give continuity to the teaching-learning process so that students can appreciate greater coherence, links, and succession of the contents of different subjects. Moreover, the definition of the PBL model will also support the enhancement of the horizontal and vertical transversal coordination among different subjects.
\end{abstract}

Keywords: Project-Based Learning, Computer Engineering, Software-oriented, Business-oriented, geolocation app.

\section{INTRODUCTION}

The current characteristics, concerns, preferences, and interests of students differ greatly from the previous students' generations. Nowadays, students are increasingly demanding active methodologies that facilitate their learning process. To meet the actual students' requirements, academic research is focused on the definition of educational mechanisms that promote greater students' participation.

So far, direct teaching has been the most used methodology in the teaching-learning process. Master classes are characterized by lecturers presenting the contents to students who usually perform some practical exercises. Then, students undergo a test in which they normally have to reproduce the contents presented by lecturers or replicate some activities such as the aforementioned practical exercises. The main weakness of this direct teaching is that it causes a repetitive and uncritical short-term memory learning [1]. Other limitations are focused on the fact that students could assimilate some content explained by the lecturers without questioning its meaning, value or even its veracity.

In order to overcome these limitations, educational research is focused on active learning methodologies whose main objective is the student-driven teaching focused on training the main typical competences of the knowledge discipline. These strategies conceive learning as a constructive and not a receptive process. Some of these methodologies are problem based-learning, case method, project basedlearning, cooperative learning, among other. This article is based on the project-based learning (PBL) that is a model that organizes learning around projects. Projects are student-driven and provide more tangible results what has been considered as a positive aspect to deepen and retain knowledge. PBL allows students to learn curricular content and put into practice key competences.

$\mathrm{PBL}$ is addressed to teach meaningful content [2]. In light of this, this methodology requires critical thinking, problem solving, collaboration and various forms of communication. Research is an essential part of the learning process as well as the need to create something new. Students must ask questions, 
seek answers, and reach conclusions that lead them to build something new: an idea, an interpretation, or a product. Moreover, the PBL is organized around a driving question. This question focuses the work of the students on important issues, debates, challenges, and/or problems.

The PBL turns the way in which information and the basic concepts are traditionally presented. In this active methodology, the process is the reverse of the direct teaching, in the sense that lecturers present the subject and concepts to the students and once that they have been internalized, students apply them to the project.

Another important characteristic of the PBL is the fact that allows students to take their own decisions as they learn to work independently and accept their responsibility in the project development. At the same time, PBL also fosters teamwork as students must listen to others' ideas to make consensual decisions related to the project development whereas each of them should be also able to clearly present their own ideas.

This methodology includes an evaluation and reflection process. Students learn how to evaluate and be valued in order to improve the quality of the project in which they work on.

Moreover, the PBL implies an audience. Students often expose their project to other students or the lecturer. This increases the students' motivation by being aware that they have an audience and also gives authenticity to the project.

Based on all these benefits, this paper is focused on all the activities performed to plan, define, design and project an integrated PBL model for students in the last years (3rd and 4th year students) of the Computer Engineering Degree. The PBL model involves the following subjects: (i) Software Engineering; (ii) Project Management; (ii) Business Requirements Analysis and (iv) Business Models and Organisation Functional Areas. The PBL model has twofold perspectives, the first one is more project and software-directed while the second one is more business-oriented. This model seeks to give continuity to the teaching-learning process so that students can appreciate greater coherence, links, and succession of the contents of different subjects. Moreover, the definition of the PBL model will also support the enhancement of the horizontal and vertical transversal coordination among different subjects.

The paper is structured as follows. Section 2 describes the PBL model proposal with the definition of the main activities that will be performed among the different subjects to provide students with a whole learning output. Sections 3 offers a proposal of indicators to assess the feasibility of this active methodology. Finally, section 4 highlights the main conclusions and the future lines of work.

\section{PROPOSAL OF THE PBL MODEL}

\subsection{Design Methodology}

The definition of the PBL model has followed the design methodology proposed by [3]. This methodology is based on the phases described in Figure 1.

In the first phase, the definition of the PBL model, different aspects have been taken into account such as: learning objectives, the appropriateness of the contents, assessment indicators, among others, in order to make that the PBL model is the result of the integration of objectives, content and evaluation criteria of different subjects.

The second phase is focused on the detailed analysis of the PBL model defined. Once that the PBL model is defined (section 2.2), aspects such as the linkage between the new knowledge generated within the project development and the students' previous experiences are studied. Other features that are examined carefully are related to the project information, in the sense that the objectives pursued, the deadlines, the tasks to be performed are clearly defined and they are understandable by students.

Another aspect to be considered in this phase is the analysis of the complexity and difficulty of the objectives pursued. The difficulty of the project resolution should be in line with the academic year, semester and the previous students' knowledge. Moreover, it is also important to take care about the offer of different learning strategies, since not all strategies are appropriate for all students. The PBL model defined in the first phase should guarantee a cooperative structure among students and be a socialization enabler. 


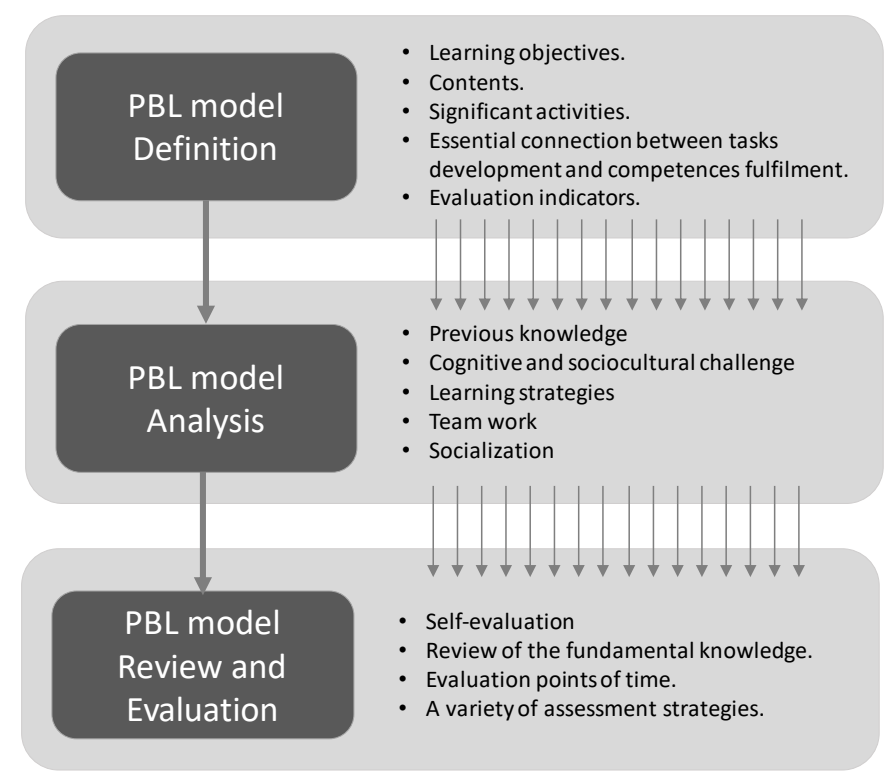

Figure 1. Methodology to define the PBL Model based on [3].

Finally, the third phase is focused on the PBL review and evaluation issues. In this final phase of the PBL model definition, self-evaluation elements should be defined as well as the adequate timeline when the different assessments should be performed. Moreover, diverse assessment strategies should be considered in order to ensure that learning has been achieved successfully.

\subsection{PBL Model}

As aforementioned, the PBL model proposal involves 4 subjects. The information related to the subjects is presented in Table 1. The PBL models consists of 10 activities, 3 of which belong to the first of the subjects, 4 activities are defined to be performed in the following two subjects and the last 3 activities will be developed in the last subject that it is taught in the fourth year of the computer engineering degree. Moreover, it is worth mentioning that two of the subjects are compulsory, that is all the students of the engineering degree have to take them while the other two subjects are optional. For this reason, the proposed model has been defined taking into account that all the activities are coordinated transversally and provides continuity to the teaching-learning process but they also have a certain degree of independence, since not all the students will be enrolled in the optional ones. The title of the PBL model is 'Software engineering in business contexts'.

Table 1. Subjects involved in the PBL model proposal.

\begin{tabular}{l|c|c|c|c}
\hline \hline \multicolumn{1}{c|}{ Subjects } & Year & Semester* & Type & Activities in the PBL model \\
\hline Software Engineering & $3^{\text {rd }}$ & A & Mandatory & 3 \\
\hline Project Management & $3^{\text {rd }}$ & B & Mandatory & 2 \\
\hline Business Requirements Analysis & $3^{\text {rd }}$ & B & Optional & 2 \\
\hline $\begin{array}{l}\text { Business Models and } \\
\text { Organisation Functional Areas }\end{array}$ & $4^{\text {th }}$ & A & Optional & 3 \\
\hline \hline
\end{tabular}

*A: From September to January, B: From February to June

To keep coherence between the different subjects, all the activities proposed throughout the PBL model should elaborate on a common topic. The selected topic should have potential to be extended and seamlessly applied to every subject. Moreover, it should be eye-catching enough to engage students, so that they feel excited and get naturally involved into the process.

Based on the consensus of all the lecturers involved in this PBL model and due to the current relevance of the COVID-19 outbreak, the project defined is related to development of a software to track user's contacts with the aim of slowing down the spread of the pandemic. In this sense the software will identify 
users who have tested positive for COVID-19 and will keep track of their geolocated position. When other users are detected to be close enough, they will be notified, and if they come into contact then they will be marked to be suspected of contagion. The application will also keep track of the suspected of contagion users, following the described process. All the information will get recorded into the system, enabling further processing and retrospective analysis.

The authors of this work believe this topic has full potential to be applied to every subject. From the more software-oriented subjects' perspective (Software Engineering and Business Requirement Analysis), the software to develop is complex enough to illustrate the different phases of the software development process and to configure multiple teams to work on it. From the more business-oriented subjects' perspective (Project Management and Business Models and Organisation Functional Areas), the basic topic may be easily extended enabling a more complex environment which includes multiple institutions and processes, becoming a major project to study. Moreover, as the application includes geolocation, it can be also useful for other purposes such as relating the location of a person with marketing aspects, by offers and/or discounts of the shops near such a person.

The project activities have been defined to be performed sequentially.

\section{+ Activity 1. Requirements' Specification.}

This activity triggers the full process and includes several subtasks. First, multiple teams of 3-5 students are set-up. Then, some details about the methodology that needs to be applied for the software development process are specified. The customer's needs and requirements are presented to the students and they are required to deliver a software requirements specification (SRS) of the product they will develop. Finally, they get trained in key technologies which will prove useful in subsequent development activities.

\section{+ Activity 2. Software Development.}

In this activity students have to develop the prototype software following the SCRUM [4] methodology. It is expected to execute 5 sprints with a duration of two weeks each one. At the beginning of each sprint, the same procedure has to be followed: 1) each team makes a presentation of the results obtained in the previous sprint, with its corresponding demo, and 2) the objectives to be fulfilled in the next sprint are "negotiated" with the customer. During each sprint, the team holds a minimum of two follow-up meetings and delivers a report with the main conclusions (sprint review).

\section{+ Activity 3. Presentation and Defense of the Software Prototype.}

In this activity, students present the results obtained. Each team presents a demonstration of the developed software prototype and conducts a critical analysis on the strengths and weaknesses of the process carried out.

\section{+ Activity 4. Initiation and Planning Phases of Project Management.}

In this activity, firstly the proposal for a project to implement the prototype developed in Activity 2 in a simulated business context is presented. After this description, different real-based problems related to the management of this simulated project are proposed to the students. They have to solve these realistic problems and to do so, students have to develop project management documentation as a real development project. These documents are not "technical" materials related purely to the software development, as this learning objective has been achieved in the first three activities, but rather the documentation is linked to the project management process, taking into account the specific characteristics of the simulated business scenario. This activity 4 will be developed based on the project management guidelines defined by the Project Management Institute [5] and will focus on the initiation and planning stages of the project management life cycle.

\section{+ Activity 5. Execution, Monitoring and Closure Phases of Project Management.}

In this activity and following the context of the project presented in Activity 4 , students will work on the project management phases of execution, monitoring/controlling and closure. Different management problems related to the app developed and based on the business context simulated are proposed. Students have to deal with these problems and propose solutions to try to find the best ways to proceed in the 3 last phases of project management. 


\section{Activity 6. Learning of the basic concepts related to process management.}

This activity involves the learning of the fundamental notions such as process map, organizational structures and process continuous improvement. During this activity, the different concepts will be shown in relation to the developed app and the business context scenarios simulated in the previous activities. The notation used the definition of business processes will be Business Process Model and Notation (BPMN) [6].

\section{+ Activity 7. Definition of uses cases.}

Once that students have already internalized the essentials of the process management, in this activity they will work with use cases and BPMN process diagrams for obtaining the organizational requirements. The use cases are based on the context of the app prototype developed in activities 1 to 3 and on the business scenario simulated in activities 4 to 6 .

+ Activity 8. Analysis of the different applications of the geolocation app prototype to customer sectors.

This activity will guide students on the analysis of technological, economic, commercial, sociological perspectives of current and existing geolocation apps that are already in the market. To do so, it is planned to perform a brainstorming session to determine application areas with the greatest potential and the selection of the target sector to work on the project.

\section{+ Activity 9. Definition of the business model of the geolocation app prototype.}

In this case, with the support of the professor, students should define the 9 elements that make up a business model. Based on the value proposition oriented to the target sector defined in the previous activity, the CANVAS [7] of the business model will be defined.

\section{+ Activity 10. Economic-financial analysis.}

The main goal of this activity is to determine the viability of the business model. Starting from the analysis of the investments required to carry it out and from the marketing and sales plan, human resources structure needed, treasury and capital needs, the main ratios are analyzed to determine the economic viability in a company (net present value - NPV, internal rate of return - IRR, maneuver fund, profitability threshold, etc.).

\section{EXPECTED GOALS}

The expected goals of this project will be assessed, based on the Project Based Teaching Rubric developed by PBLWorks.org [8] through 6 aggregated indicators that are the ones defined in Figure 2 .

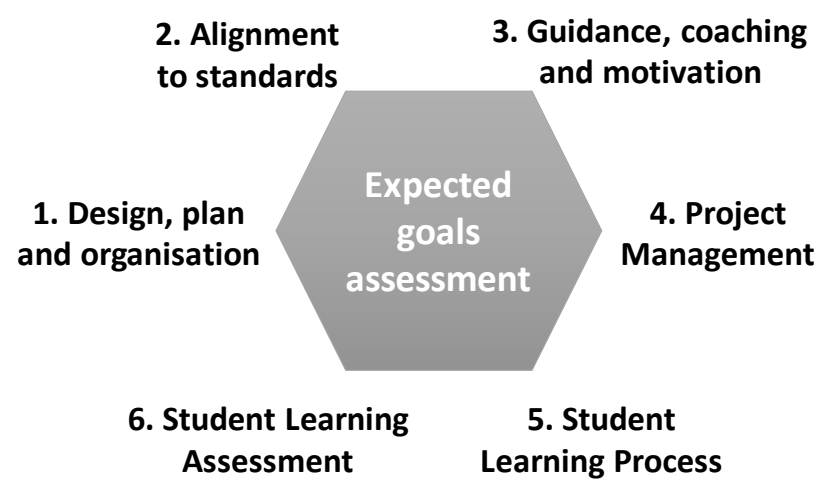

Figure 2. Expected goals assessment through aggregated indicators.

The different items to be considered for the assessment of each aggregated indicator are defined as follows:

- Design, plan and organisation

- Project includes all vital project design elements.

- Plans are comprehensive and include supporting and assessing students' learning process. 
- All the necessary resources for the project have been forecasted to the fullest extent possible and arranged well in advance.

- Alignment to standards

- Criteria for the projects are clearly and specifically derived from standards.

- Scaffolding of student learning, critique and revision protocols, assessments and rubrics consistently refer to and support student achievement of specific standards.

- Guidance, coaching and motivation

- The guidelines for the project development are clearly described and agreed between students and professors.

- Students usually find out what they need to do with minimal guidance from the professor.

- Students work collaboratively in healthy, high-functioning teams; the teacher rarely needs to intervene to resolve conflicts.

- Students understand there are different ways to fulfil the driving question and complete the project, and they take risky decisions, sometimes they are wrong, but they learn from mistakes.

- The values of critique and revision, persistence, rigorous thinking, and pride in doing highquality work are shared, and students hold each other accountable to them.

- The expectations for the performance of all students are clearly established, shared, and reinforced by professors

- Regular reflections about the project are performed among students and professors to reorient the project development path when necessary or to celebrate gains and accomplishments.

- Project Management

- Classroom procedures and rules are regularly followed during project development to maximize productivity.

- All the project management mechanisms put available for students are used to support student self-management and autonomy.

- The project calendar is adequate to perform all the activities sequentially or in parallel as well as the time scheduling.

- Student Learning Process

- Student receive necessary instructional supports to access content, skills, and resources; these supports are removed when no longer needed providing them independence.

- The learning process is students' driven by questions and needs, the professor gives the necessary details about the project at the beginning, but he/she does not overinform students.

- A huge and diverse variety of a learning mechanism, tools and strategies are provided to students.

- Students' research and investigation is facilitated, while encouraging students to act and think as independently as possible

- Student Learning Assessment

- Project outputs are used to carefully assess subject-area standards as well as acquired competences.

- Students are individually and collaboratively assessed.

- Constructive assessment is used frequently, with a variety of tools and processes.

- Coordinated procedures for critique and review are used frequently at checkpoints to assess the milestones achievement level.

- Students give and receive helpful feedback to take further project decisions.

- Frequent and well-defined advice is provided for students to support their self-assessment and also the performance of peers.

- Rubrics are used by students and the professors throughout the project to guide assessment.

Once the new methodology is implemented, these items will serve through questionnaires for both involved students and teachers, as a checklist to contrast its correct implementation. 


\section{CONCLUSIONS}

This work represents the effort of integrating four different subjects coming from two complementary disciplines (software development and business) in the last courses of the Computer Engineering Degree. Project-based learning (PBL) has been the selected instrument to achieve such integration, fostering students to collaborate, solve challenges, build new knowledge and apply it to real cases, putting into practice key competences.

One of the keys to succeed in the process involves selecting a stimulating topic which triggers students' curiosity and leads them to get involved into the project in a natural way. In addition to proposing a COVID-19 related software development, all the activities included in the model have been described and the authors have planned to implant them in next courses.

Even though the implementation has been not already performed yet, authors firmly believe that by applying this methodology students will obtain a number of benefits, such as long-term knowledge, team work and/or discussion, besides being able to easily identify connections between the involved subjects, instead of considering each subject as an isolated knowledge cluster. In this sense, multiple indicators have been identified and listed. Once the methodology is applied and all the indicators evaluated, a clear picture about the benefits of the presented approach will be published.

\section{ACKNOWLEDGEMENTS}

This article has been supported by the Vice-rectorate for Digital Resources and Documentation (Vicerrectorado de Recursos Digitales y Documentación) and Vice-Rectorate for Studies, Quality and Accreditation (Vicerrectorado de Estudios, Calidad y Acreditación) under the Call for Learning + Teaching (Convocatoria Aprendizaje + Docencia (A+D 2019)) and Project Code: 1678-A. The authors would like to acknowledge the support of the Institute of Educational Sciences (Instituto de Ciencias de la Educación) of Universitat Politècnica de València, the Evaluation and Monitoring Commission for Educational Innovation and Improvement Projects (Comisión de Evaluación y Seguimiento de Proyectos de Innovación y Mejora Educativa - CESPIME) and Escuela Politécnica Superior de Alcoy.

\section{REFERENCES}

[1] B.J. Duch, S.E. Groh, D.E Allen. The Power of Problem Based Learning. Stylus 2001

[2] J. Larmer, J.R. Mergendoller, "The main course, not dessert". Buck Institute for Education, pp. 1-4, 2010.

[3] Conecta13. "Cuestionario de Valoración de Proyectos."

[4] Schwaber, Ken, and Mike Beedle. Agile software development with Scrum. Vol. 1. Upper Saddle River: Prentice Hall, 2002

[5] W.R. Duncan. The process of project management. Project Management Journal, vol. 24 no. 3, pp. 5-10, 1993.

[6] OMG, "BPMN 2.0.2" Release Date: January 20, 2014. Retrieved from www.omg.org/spec/BPMN/2.0.2/PDF/

[7] A. Osterwalder, A., Y. Pigneur. Business model canvas. Self published. 2010

[8] Buck Institute for Education."Project Based Teaching Rubric". 2019. Retrieved from PBLWorks.org 